This item was submitted to Loughborough's Research Repository by the author.

Items in Figshare are protected by copyright, with all rights reserved, unless otherwise indicated.

\title{
Integrating systemic accident analysis into patient safety incident investigation practices
}

\section{PLEASE CITE THE PUBLISHED VERSION}

https://doi.org/10.1016/j.apergo.2018.04.012

\section{PUBLISHER}

(C) Elsevier

\section{VERSION}

AM (Accepted Manuscript)

\section{PUBLISHER STATEMENT}

This work is made available according to the conditions of the Creative Commons Attribution-NonCommercialNoDerivatives 4.0 International (CC BY-NC-ND 4.0) licence. Full details of this licence are available at: https://creativecommons.org/licenses/by-nc-nd/4.0/

\section{LICENCE}

CC BY-NC-ND 4.0

\section{REPOSITORY RECORD}

Canham, Nye, Gyuchan Thomas Jun, Patrick Waterson, and Suzanne Khalid. 2019. "Integrating Systemic Accident Analysis into Patient Safety Incident Investigation Practices". figshare.

https://hdl.handle.net/2134/33173. 
Integrating Systemic Accident Analysis into Patient Safety Incident Investigation Practices

Aneurin Canham ${ }^{1}$, Gyuchan Thomas Jun ${ }^{1}$, Patrick Waterson ${ }^{1}$ and Suzanne Khalid ${ }^{2}$

${ }^{1}$ Human Factors and Complex Systems Group, Loughborough Design School, Loughborough University, Loughborough, UK

${ }^{2}$ University Hospitals of Leicester NHS Trust, Leicester, UK 


\title{
Integrating Systemic Accident Analysis into Patient Safety Incident Investigation Practices
}

Abstract: 153 words. Manuscript text: 4429 words.

\begin{abstract}
There is growing awareness of the limitations of current practice regarding the investigation of patient safety incidents, including a reliance on Root Cause Analysis (RCA) and a lack of safety expertise. Human Factors and Ergonomics (HFE) can offer safety expertise and systemic approaches to incident analysis. However, HFE is underutilised in healthcare. This study aims to explore the integration of HFE systemic accident analysis into current practice. The study compares the processes and outputs of a current practice RCA-based incident analysis and a Systems Theoretic Accident Modelling and Processes (STAMP) analysis on the same medication error incident. The STAMP analysis was undertaken by two HFE researchers with the participation of twenty-one healthcare stakeholders. The STAMP-based approach guided healthcare stakeholders towards consideration of system design issues and remedial actions, going beyond the individual-based remedial actions proposed by the RCA. The study offers insights into how HFE can be integrated into current practice.
\end{abstract}

\section{Keywords}

Patient safety; incident analysis; systemic accident analysis 


\section{Introduction}

High risk industries such as aviation, nuclear, rail and healthcare use accident and incident investigation to learn from failure and create action plans to avoid future incidents (Salmon et al., 2011). Within healthcare there is growing awareness of issues with current practice in incident investigation, with questionable quality of investigations and analysis resulting in ineffective recommendations and action plans (Wu et al., 2008; Peerally et al., 2016; Kellogg et al., 2016). Limitations identified include an over reliance on the promotion of a single flawed reductionist approach, Root Cause Analysis (RCA) and a lack of utilisation of external safety expertise (Wu et al., 2008; Peerally et al., 2016; Kellogg et al., 2016). Human Factors and Ergonomics (HFE) has developed expertise in systems safety and applied various systemic approaches to incident analysis. HFE's systemic accident analysis and system design approaches have been developed for use in complex work systems (Leveson, 2012; Hollnagel, 2012; Rasmussen, 1997) and are judged to be better suited to forming an understanding of accidents in complex high-risk industries, as compared to traditional causal event chain techniques, such as Root Cause Analysis (Salmon et al., 2011; Leveson, 2004; Hollnagel, 2004).

The potential of systemic accident analysis in healthcare such as Systems-Theoretic Accident Model and Processes (STAMP) (Leveson, 2004), AcciMap (Rasmussen and Svedung, 2000) and Functional Resonance Analysis Method (FRAM) (Hollnagel, 2012) has been demonstrated through analysis undertaken by experienced external method experts (e.g. Leveson et al., 2016; Karsh et al., 2014; Alm and Woltjer, 2010). However, systemic accident analysis has had little exposure to healthcare stakeholders that undertake incident investigations in current healthcare practice. A 
potential avenue for HFE to have a beneficial impact on healthcare is by facilitating healthcare stakeholders to apply systems approaches to their incident investigation (Waterson and Catchpole, 2016).

The current study aims to investigate the application of an HFE-led systems approach to healthcare incident analysis. Taking into account the time constraints of healthcare stakeholders the study asks how collaboration between HFE and healthcare can facilitate system thinking and guide analysis towards recommendations of more effective remedial actions.

\section{Methods}

\subsection{Setting}

The study is centred on a medication error incident (an insulin overdose case from a prescription error) involving two healthcare providers in the UK serving a population of around one million; an acute trust employing over 14,000 staff with a 900-bed hospital and a trust providing community health services which employs over 5,000 staff. The incident involved a patient being administered an overdose of insulin on three occasions following a drug prescription error. Drug prescription errors have previously been identified as the most common type of medication error (Leape et al., 1995; Bates et al., 1995) and in the UK, it is believed that up to $1.5 \%$ of hospital prescriptions may contain a medication error (Dean et al., 2002).

The events leading up to the incident can be summarised as: A patient was admitted to a hospital emergency department following a fall at home and subsequently transferred between wards. After being found to have high blood glucose level a review by a diabetes specialist nurse (DSN) suggested the patient to start insulin 
glargine U100 10 units once per day. The recommended dosage was misread by the prescribing doctor and 100 units were prescribed instead of 10 units. The high dosage was administered twice at one provider ward and then following discharge to another provider ward, a further time before the error was identified by an advanced nurse practitioner.

\subsection{Incident analysis: current practice}

Prior to this study, a formal investigation of this incident was undertaken through Root Cause Analysis by a team of healthcare professionals following the National Patient Safety Agency (NPSA) level one investigation profile (NPSA, 2008): Level one is a most commonly used concise investigation for incidents that resulted in no, low or moderate harm to the patient. This investigation team included an investigation chair, 2 team leads and 7 team members. Information gathered by this team included interviews with key staff involved in the incident, statements from nursing and medical staff involved in the incident, a review of an incident report form, review of medical and nursing records, and review of procedures and protocols. The report from this investigation was subsequently used as the initial basis for the systemic accident analysis and the results from both analyses were compared.

\subsection{Systemic accident analysis}

Based on the RCA-based investigation report, a systemic accident analysis approach using Systems Theoretic Accident Modelling and Processes (STAMP) (Leveson, 2012) was applied through two healthcare stakeholder workshops facilitated by two Human Factors and Ergonomics (HFE) researchers with the following profiles: 
1. Junior HFE researcher, a graduate member of the Chartered Institute of Ergonomics and Human Factors (CIEHF) whom had previously graduated from an MSc in Ergonomics and Human Factors, currently PhD researcher on healthcare systems ergonomics. This researcher acted as the main facilitator and analyst.

2. Senior HFE researcher, a Chartered Ergonomist and Human Factors specialist and Lecturer in systems HFE with 14-year research experience in healthcare ergonomics. This researcher oversaw and supervised the analysis.

The two HFE researchers conducted an initial STAMP-based incident analysis based on the data from the RCA report. The STAMP approach was chosen due to its application of systems theory and detailed analysis of the behaviour shaping mechanisms in the decision-making of individuals. This has been shown to be a powerful combination in understanding why an accident happened and how to best design remedial actions to prevent future occurrence, with some evidence of successful use in a healthcare context (Leveson et al., 2016).

STAMP describes an accident in terms of a hierarchy of control based on adaptive feedback mechanisms and models the hierarchical safety control structure present in the system to enforce safety constraints (Leveson, 2012). This type of approach to accident analysis aims to overcome the limitations in explaining accidents in terms of events, acts and errors (Leveson, 2012; Hollnagel, 2012; Rasmussen, 1997; Rasmussen et al., 1990). A general example of a safety control structure model is adapted for hospital application and provided in Figure 1. The control structure contains downwards arrows showing a reference channel with the information necessary to impose safety constraints on the level below and upwards arrows that 
show the measuring channel with feedback returned up the hierarchy on how effectively constraints are being satisfied (Leveson, 2015).

\section{SERVICE DEVELOPMENT}

Government

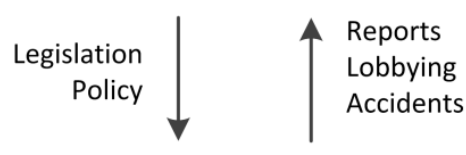

Regulatory Agencies

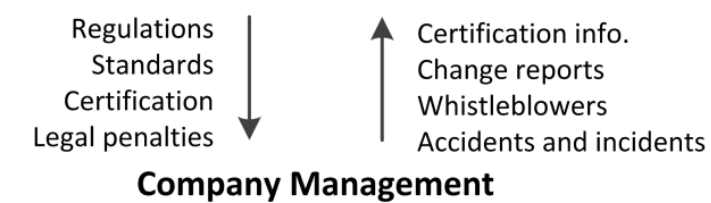

Purchasing policy Recruitment policy

Training policy Information policy

\section{Change Management}

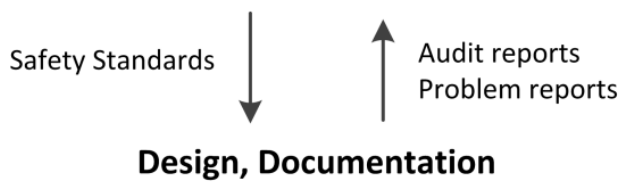

Safety constraints
Standards
Test requirements
Status reports Risk assessment Incident reports

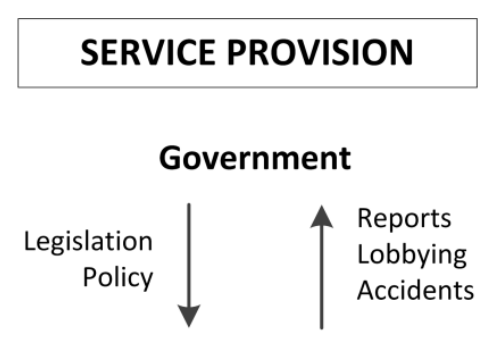

Regulatory Agencies

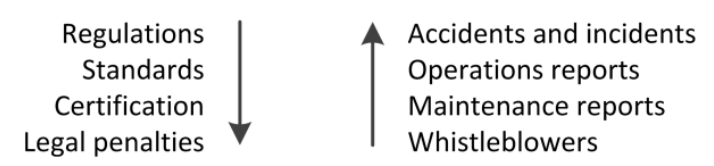

Company Management

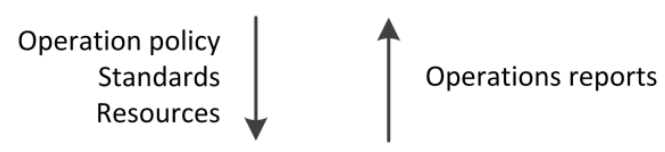

Operations Management

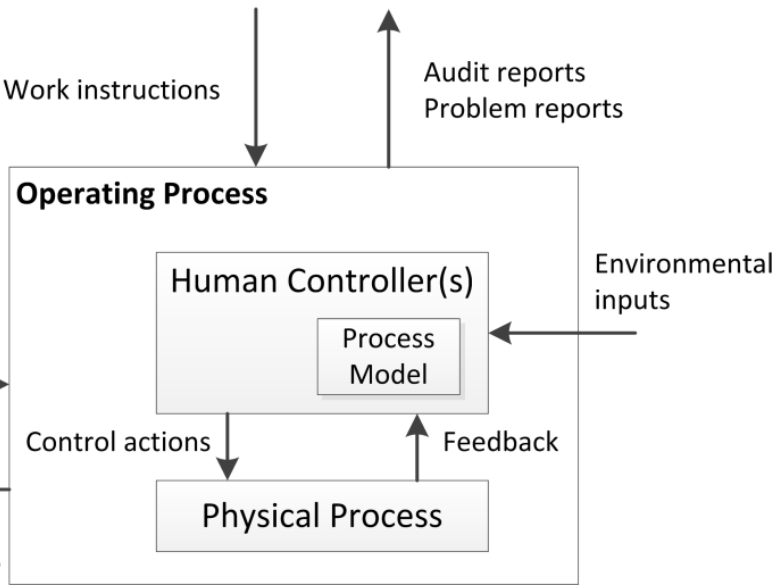

Figure 1 Generic safety control structure for hospital. Adapted from Leveson, 2004

The process of applying STAMP to accident analysis is described fully elsewhere (Leveson, 2012), here it is simplified and summarised into the following eight steps:

1. Identify the system and hazard involved in the incident

2. Identify the safety-related constraints and responsibilities, associated with that incident 
3. Document the safety control structure in place to enforce the safety constraints and control the hazard

4. Determine the proximate events leading to the incident and analyse the frontline operations present at the lower level of the control structure

5. Analyse the higher levels of the control structure determining how and why these managerial levels contributed to the inadequate control of the hazard

6. Examine overall coordination and communication issues between controllers that could have contributed to the incident

7. Determine any changes and weakening in the control structure that occurred over time and contributed to the incident

8. Generate recommendations for remedial action and strengthening of the safety control structure (Leveson, 2012)

The application of STAMP in this study contained several stages and these are summarised in Table 1 with detail on the people involved and the time taken to complete. Two HFE researchers carried out step 1-3 prior to step 4-8, which were carried out with healthcare staff.

For step 1-3, two HFE researchers carried out the reanalysis of the RCA report using STAMP. The two researchers created a draft safety control structure model to be utilised in the subsequent healthcare stakeholder workshops.

Table 1 Systemic accident analysis process

\begin{tabular}{llll}
\hline Steps & People involved & Means (time) & Outputs \\
\hline $\begin{array}{l}\text { STAMP step 1-3 } \\
\text { (Reanalysis of the RCA } \\
\text { report) }\end{array}$ & $\begin{array}{l}\text { Senior and junior HFE } \\
\text { researchers }\end{array}$ & 5 hours & Safety control structure \\
\hline $\begin{array}{l}\text { Preparation of material } \\
\text { for workshops }\end{array}$ & $\begin{array}{l}\text { Senior and junior HFE } \\
\text { researchers }\end{array}$ & 8 hours & $\begin{array}{l}\text { Safety control structure } \\
\text { templates } \\
\text { Step-by-step method } \\
\text { guide }\end{array}$ \\
\hline
\end{tabular}




\subsection{Workshops}

This study aimed to involve healthcare stakeholders in the systemic accident analysis with facilitation by external HFE researchers, since it is imperative to involve them to act as subject matter experts to validate STAMP's system models (Hettinger et al., 2015) and develop more relevant and effective recommendations for change. This was done through two workshops; the workshops introduced accident analysis concepts and the STAMP approach presented by an HFE researcher. Following the introduction, the safety control structure system model was provided to the participants and they were invited to take part in the analysis using a step-by-step method guide. The first workshop aimed to develop recommendations for remedial action, in addition to this the second workshop aimed to evaluate the utility and usability of STAMP with feedback from the original RCA investigation team. 


\subsubsection{Workshop 1}

The first workshop was 3 hours in duration with 18 attendees from healthcare including members of local commissioning groups, patient safety managers, front line staff and patient representatives, facilitated by 3 HFE researchers. All of the participants were from the same regional healthcare where the incident occurred, but none of them were involved in the original RCA investigation. Following the introduction to STAMP the participants were asked to participate in the incident analysis, working in 3 separate groups each with a safety control structure system model, method guide and facilitation by an HFE researcher.

\subsubsection{Workshop 2}

The second workshop was 2 hours in duration and facilitated by the 2 HFE researchers. The workshop was attended by 4 healthcare professionals (with an average of 31 years healthcare experience), including 3 involved in the original RCA investigation. During this workshop, following the presentation of the concepts of STAMP, the safety control structure system model was validated and the participants were invited to contribute to the analysis, using the model and STAMP concepts as discussion points. At the end of the workshop the participants were asked to give feedback on the utility and usability of the STAMP approach. This workshop was audio-recorded. 


\section{Results}

\subsection{Processes - Comparison between HFE-led STAMP and current} practice RCA

Key information from the RCA and STAMP processes is presented in Table 2. Along with the different analysis methods used, there were differences in the people involved, their areas of expertise and the approach to group work. The timescales set for completion of the investigation in the UK policy is 60 working days including 15 days for internal governance approval. The actual time taken for the RCA process for this case was not recorded, but the team usually carry out investigation whilst still holding their clinical case load. A comparison of the time taken for each approach isn't made but the HFE-led analysis required an additional 26 working hours by HFE experts to the previously completed investigation.

Table 2 RCA and STAMP processes

\section{RCA}

\section{People involved Assistant Chief Nurse}

Patient Safety Coordinators

Diabetes Consultant

Consultant Nurse

Lead Specialist Nurse

Education and Practice Development

Lead

Senior Diabetes Specialist Nurse

Medication Safety Lead Pharmacist

Consultant Nurse

\begin{tabular}{ll}
\hline Expertise & Work domain \\
\hline Time taken & Unrecorded \\
\hline Data used & Interviews and written statements from \\
& staff involved in incident \\
& Incident report form \\
& Medical, nursing and electronic records \\
& Procedures and protocols
\end{tabular}

Collaborative

work

Meeting

Review group

Analytical

Linear cause-effect model with

contributory factors

\section{STAMP}

HFE researchers
Healthcare stakeholders

Original investigation team members:

Senior Diabetes Specialist Nurse Medication Safety Lead Pharmacist Consultant Nurse

HFE with work domain input

26 hours

RCA report

Healthcare staff involvement in workshops

approach

Workshops

Systemic model with controlfeedback focus 
The RCA investigation was led by two Patient Safety Coordinators with a team of seven clinical staff and chaired by an Assistant Chief Nurse. The RCA used data from interviews and documentation which was analysed using time line, fishbone diagram and incident decision tree tools. This process can be described as predominantly work domain expertise led, using a linear cause effect analysis model.

In contrast, the STAMP process was led by HFE expertise, with the facilitated participation of work domain experts through workshops, using a systemic accident analysis model.

\subsection{Outputs - Comparison between HFE-Ied STAMP and current practice RCA}

The RCA identified a root cause in the prescription error by the doctor following misinterpretation of the specialist nurse recommendation, stated as human error. Incorrect dose administration by the nurses was also identified as a service/care problem. These two issues were then the subject of further analysis using the incident decision tree and fishbone diagram.

The RCA approach uses a contributory factors classification framework (NPSA, 2009) and maps identified factors to an Ishikawa fishbone diagram (Ishikawa, 1982; NPSA, 2016) as seen in Figure 2. The classification framework encourages identification of contributory factors from an individual to organisational level and presents these in list form. 


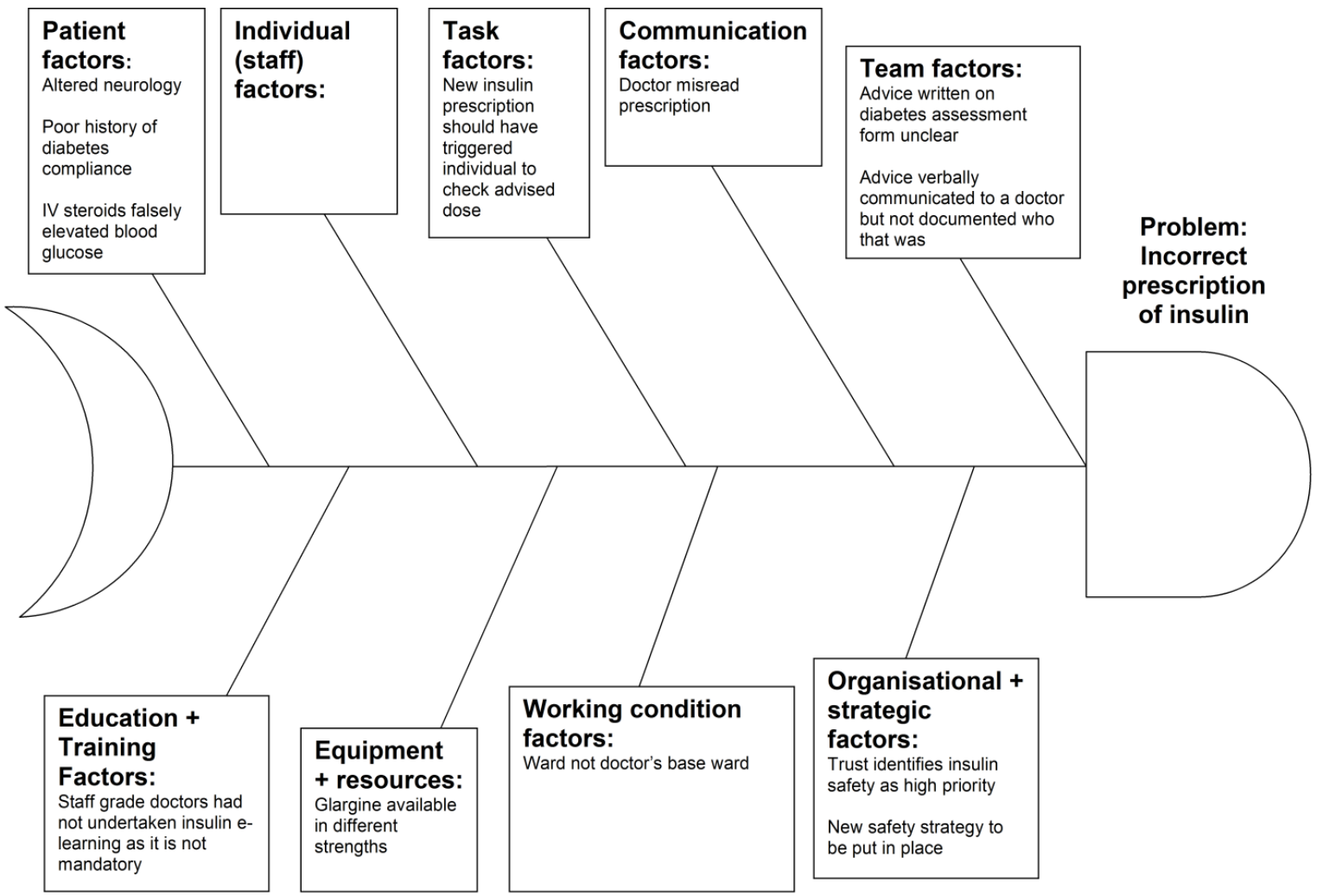

Figure 2 RCA Fishbone diagram

The RCA can be contrasted with the STAMP approach where a qualitative model of the system is formed which includes modelling relationships and interactions between system components through control-feedback loops, as shown in Figure 3. 


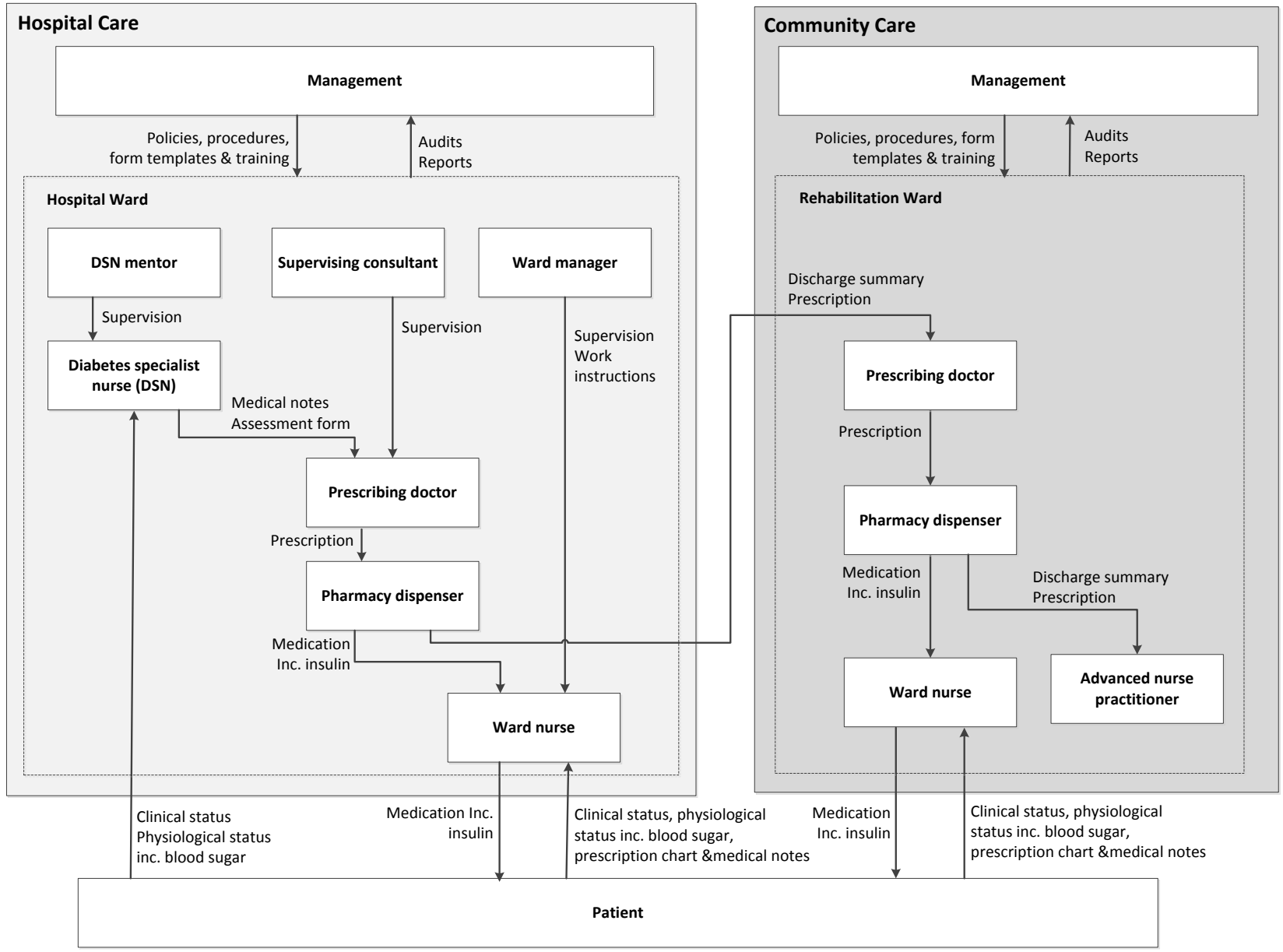

Figure 3 Safety control structure for insulin prescription and administration (simplified for readability)

STAMP's safety control structure model is used to identify weaknesses in the control structure and control-feedback flaws. STAMP considers four types of hazardous control actions (Leveson, 2012):

i. Control actions necessary to enforce safety constraint are not given (control action not given)

ii. The necessary control actions were provided too early or too late (incorrect timing)

iii. Unsafe control actions were provided (unsafe control action given)

iv. Control action stops too soon or is applied too long (incorrect duration)

STAMP also analyses the behavioural shaping mechanisms for decision-making of the actors within that system in terms of a process or mental model. This being the 
actor's understanding of current system status which needs to be regularly updated. The mental model of a decision maker can be incorrect due to poor feedback and incorrect information about system status as illustrated in Figure 4. The identified control flaws are compared with the contributory factors identified by the RCA in Table 3.

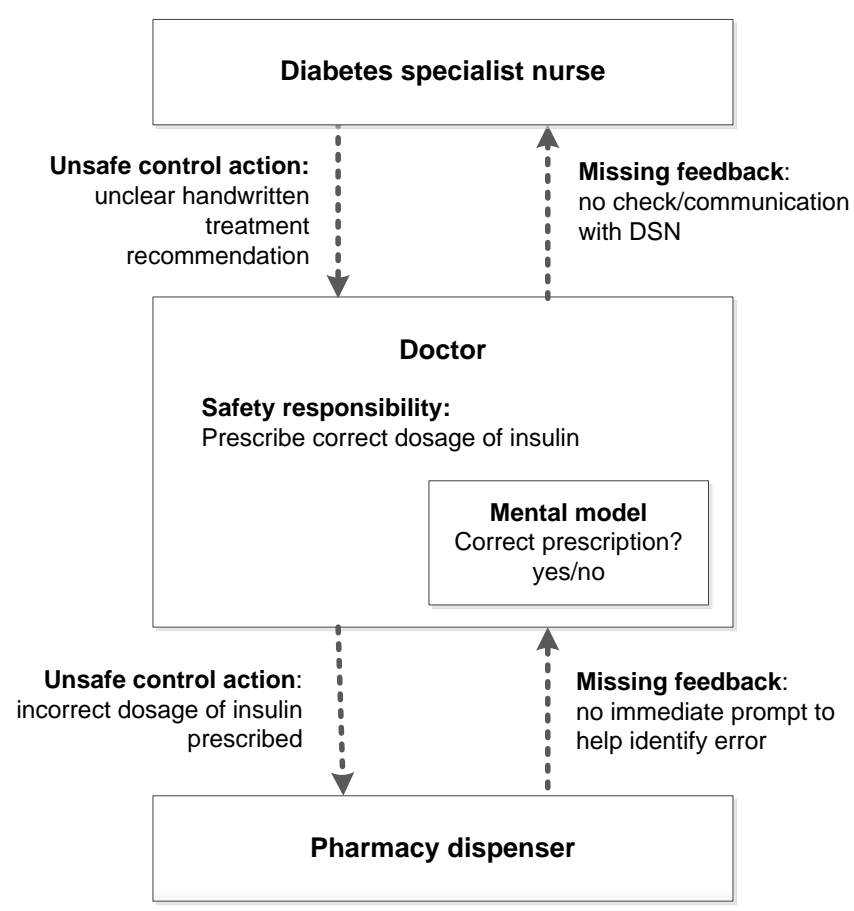

Figure 4 STAMP analysis of individual controller 
Table 3 RCA contributory factors and STAMP control flaws

\begin{tabular}{ll}
\hline System level & RCA identified contributory factors \\
\hline $\begin{array}{l}\text { Diabetes } \\
\text { specialist nurse }\end{array}$ & $\begin{array}{l}\text { Ambiguity in the recommendations in terms of written } \\
\text { clarity }\end{array}$
\end{tabular}

specialist nurse clarity

Doctor (hospital)

Failure to further query the

recommended dose

Patient: Altered neurology, poor history of diabetes compliance. IV steroids falsely elevated blood glucose

Task: New prescription should trigger check of dose Communication: Misread prescription

Team: Advice written on form was unclear Training: Insulin e-learning not mandatory Working condition: Not doctor's base ward Equipment: Glargine available in different strengths

Nurse (hospital) Individual: Both nurses in post for 12 months or less with no previous competency issues

Failure to query Task: Glargine medication stock was on ward

dose of the Communication: Dose not cross checked between form

insulin prescribed completed by specialist nurse and doctor's prescription

Team: Both nurses part of an established team

Training: Insulin e-learning not mandatory for staff

Working condition: Prescription completed on form, not electronic prescribing

Pharmacy Missed opportunity to identify the error when prescription

(hospital)

checked prior to the patient being transferred

\section{STAMP identified control flaws}

Control flaw: Issue in communication and coordination with prescribing doctor

Mental model: Recommendation correctly interpreted and correct prescription made

Feedback flaw: No feedback post recommendation

Control actions not given: Doctor did not question high recommended dosage or review suggestion thoroughly

Mental model: Incorrect understanding of patient status and required prescription

Feedback flaw: Coordination and communication issue in handwritten notes and lack of face-to-face handover at time of writing prescription

No feedback after prescription made

Control action not given: Nurse did not query the dosage except for with peers and did not cross-check with specialist nurse documentation or patient notes

Mental model: Accepted doctor's prescription as correct.

Nurses recognised prescription as a large dose but they had seen large doses of insulin prescribed before

Feedback flaw: The charts readily available to ward nurses had high dosage on them. The nurse questioned between themselves but not to specialist nurse or senior staff

Control action not given: Pharmacy did not cross-check prescription against patient records (medication stock was on ward). Prescription was checked prior to patient being transferred but issue not identified

Mental model: Prescription is appropriate

\begin{tabular}{ll}
$\begin{array}{l}\text { Organisational } \\
\text { (hospital) }\end{array}$ & $\begin{array}{l}\text { Insulin safety identified as a high priority and } \\
\text { implementation of a new safety strategy has begun } \\
\text { A team of specialist diabetes nurses has been } \\
\text { established }\end{array}$ \\
\hline $\begin{array}{l}\text { Nurse } \\
\text { (Community) }\end{array}$ & $\begin{array}{l}\text { Previous administration of dose and discharge } \\
\text { documentation provided rationale for nurse to administer } \\
\text { dosage }\end{array}$
\end{tabular}

Control action provided too late: Assessment form documentation not in format currently advised. Not updated until triggered by incident

Control action not given: Nurse did not query the dosage

Mental model: Accepted prescription as correct

Feedback flaw: Medication dosage had been administered twice previously and on discharge documentation 
The RCA focussed on the hospital doctor and nurses and the factors contributing to their involvement in the incorrect prescription and administration. The use of an incident decision tree tool, that seeks to determine the actor's intention and blameworthiness of human error (Reason, 1997; Meadows et al., 2005), absolves those actors of blame, but this focus means less attention is paid to other areas of the system, as shown in Table 3.

A major difference between RCA and STAMP is in STAMP's modelling of the system. RCA does not model the relationships between system components and it does not build a model of the system. Contributory factors are attached to the identified service problem and presented in list form, whereas the control-feedback relationships presented in STAMP's safety control structure provide analysis of interactions within the system.

Another major difference is in STAMP's explicit consideration of both the system operation and the system development or design as shown in Figure 1. The consideration of system design led the analysis to question the change management processes regarding specification, design, evaluation and approval of new information templates/forms to be used in a hospital. There was also questioning about the design of information systems, with information given to the prescribing doctor split between electronic and paper format.

\subsection{Recommendations}

Both analyses produced recommendations to prevent future incidents, with a summary of these presented in Table 4. In comparing the analyses recommendations, STAMP generated additional recommendations for system-level improvement, especially with 
consideration that two system-level improvements from RCA referred to the initiatives which were already being conducted prior to the incident: i) the review and implementation of the new diabetes assessment form; ii) the implementation of insulin strategy. The RCA-based recommendations focussed on staff training and personal reflection, whereas the STAMP analysis broadened the discussion and recommendations to systemic issues (service development and change management), rather than just the operation management issues.

Table 4 Recommendations for remedial action from two approaches

\begin{tabular}{|c|c|c|}
\hline $\begin{array}{l}\text { Category of } \\
\text { countermeasure }\end{array}$ & RCA-based recommendations & STAMP-based recommendations \\
\hline Individual behaviour & $\begin{array}{l}\text { - Personal reflection to be } \\
\text { undertaken } \\
\text { - Roll out and ensure compliance } \\
\text { to insulin safety e- learning for all } \\
\text { medical and nursing staff }\end{array}$ & $\begin{array}{l}\text { - Ensure doctors, nurses and } \\
\text { pharmacists are given clear safety } \\
\text { responsibilities (check and query) and } \\
\text { understand these responsibilities }\end{array}$ \\
\hline $\begin{array}{l}\text { Tools, technology and } \\
\text { physical environment }\end{array}$ & $\begin{array}{l}\text { - Review and implement new } \\
\text { diabetes assessment form }\end{array}$ & $\begin{array}{l}\text { - Review and implement new diabetes } \\
\text { assessment form } \\
\text { - Review electronic information system } \\
\text { for potential inclusion of DSN treatment } \\
\text { recommendation } \\
\text { - Feedback to pharmaceutical company } \\
\text { about name of medication }\end{array}$ \\
\hline $\begin{array}{l}\text { Tasks and } \\
\text { organisation }\end{array}$ & $\begin{array}{l}\text { - Implement insulin safety strategy } \\
\text { (on-going) }\end{array}$ & $\begin{array}{l}\text { - Ward management to regularly } \\
\text { reinforce to nurses the expectation to } \\
\text { query prescriptions where there is a } \\
\text { concern regarding dose or } \\
\text { administration instructions } \\
\text { - Ensure channels of enquiry to ward } \\
\text { leadership or original treatment team } \\
\text { are available } \\
\text { - Ensure prescribers, dispensers and } \\
\text { administrators of medication have } \\
\text { comprehensive and clear information of } \\
\text { patient status and treatment plan } \\
\text { - Train DSN's as prescribers to enable } \\
\text { them to prescribe insulin at time of } \\
\text { patient assessment } \\
\text { - Design process to include DSN check } \\
\text { with patient after administration of } \\
\text { medication }\end{array}$ \\
\hline
\end{tabular}


- Revise the design process (specification and testing) for form templates and other electronic and paper based information systems.

- Revise the documentation review process. The review process needs to be able to efficiently manage change, with timely review and implementation of new documentation

- Ensure future design of software includes specification and assessment of user needs

\subsection{HFE analysis workshop participant feedback}

The HFE researchers were not qualified healthcare professionals with the healthcare stakeholders played a vital role in providing work domain knowledge. The healthcare stakeholders contributed to the analysis and generation of recommendations. Feedback on the STAMP approach from the participants of the second workshop was generally positive; with all 4 participants agreeing that STAMP was useful in learning from the incident and that they would make additional recommendations based on the approach. The participants found the approach helped them think about the incident in a systemic way as shown in the following quotes by those who were involved in the original RCA investigation.

'The approach enables us to think more broadly about system controls and failure points'

'Previously I felt my team were really to blame, but now I understand it was multifactorial' 'It made me think of the interactions between people. All the groups/individuals involved' 
On future application, all of them indicated that further experience with the method and HFE experts' help would be required.

\section{Discussion}

This study has applied an HFE-led systemic accident analysis approach to healthcare incident analysis and demonstrated STAMP's potential in healthcare. The use of STAMP and collaboration between HFE and healthcare stakeholders was found to facilitate systems thinking, impacting the thinking of some of the original investigators of the incident and guided the development of underlying system-based recommendations.

\subsection{Current practice and benefit of HFE input}

Although the HFE-led systemic accident analysis approach has proven useful, it is difficult to determine how much of the observed effect on analysis outcomes was due to the use of STAMP and how much was due to the presence and facilitation of HFE practitioners in the present study. The lack of knowledge about STAMP in healthcare meant the healthcare investigators were not capable of using it alone and it is assumed both HFE practitioner presence and use of a different accident model in STAMP contributed to the effect on analysis outcome. Previous research has suggested accident investigation and incident analysis can be influenced by several factors including the background and knowledge of the analyst (Rasmussen et al., 1990; Lundberg et al., 2010), the accident model used (Lundberg et al., 2009), the time and resources available for the investigation and proposed remedial actions being constrained by practical considerations (Lundberg et al., 2010). 
Within this case study, groups with different backgrounds have taken part in the incident analysis; Healthcare stakeholders with specialist knowledge on the work domain and HFE researchers with HFE knowledge. Work domain knowledge is a vital part of the analysis and already seen as such, here it is argued that HFE knowledge is also a vital component for good quality analysis outcomes. With neither group of analysts holding the requisite knowledge from both domains a collaboration was needed. This collaboration has its challenges such as the limited time healthcare stakeholders can give and communication between the two professional groups with their different technical terms and jargon.

In this study, the healthcare stakeholders were exposed to a specialist systemic accident analysis technique which is considered a difficult approach to use even by experienced investigators (Underwood et al., 2016). The healthcare stakeholders contributed to the systemic analysis but felt they would need support and further experience to apply the approach in future. On reflection, the facilitation by HFE experts can be more effective if focus is on the main thinking behind the systems approach rather than spending too much time on the details of STAMP, especially with time constraints considered.

The use of a systemic accident model on top of the RCA cause-effect model will also influence the analysis outcome (Hollnagel, 2006; Lundberg et al., 2009). STAMP contains a combination of systemic thinking with qualitative systems modelling and detailed analysis of human decision making. While RCA included identification of contributory factors to incidents it lacked a description or explanation of the relationships and interactions between humans and components across the system. With 
contributory factors presented in list form rather than providing efforts of system modelling. This limits the understanding of how these factors impacted on human decision making. The increased understanding of relationships and mechanisms formed in STAMP is shown to be of benefit to the development of remedial actions.

\subsection{Proposed remedial actions}

The initial healthcare staff led RCA analysis produced outcomes and remedies consistent with previous RCA investigations for drug error, with outcomes commonly reliant on staff education, which is reported as being a weak remedy in addressing adverse events (Mills et al., 2008). The HFE-led systemic analysis in this case proposed remedial actions to address system level issues, such as change management in service development.

Consideration of the time it takes to undertake an investigation and the healthcare stakeholder time used up in the analysis is always prominent. Certainly, the HFE systemic analysis brought up questions that could be further analysed if time allowed. for example, the role of the pharmacy in checking the prescription which was only touched on.

The type of remedial actions proposed and implemented after incident investigations are not only influenced by what is found in the analysis. Research involving interviews with investigators from multiple industries, including healthcare, has shown remedial actions are dependent on several factors including: what the analyst/organisation knows how to fix; if the remedies are possible to fix and under control of the organisation; and cost-benefit balance (Lundberg et al., 2010). The commonly proposed healthcare 
remedial actions of staff training and small policy change (Kellogg et al., 2016) are likely to be proposed due to the organisation knowing how to implement them, being under the control of the organisation and being easier (and cheaper) to implement than deep systemic issues. Indeed, many of the remedies suggested by the STAMP analysis would need further understanding and specification prior to implementation. Remedies such as changes to computerised systems are a serious undertaking, which may make analysts reluctant to propose this type of recommendation. Immediate actions might not be possible for such system-based interventions, but healthcare organisations can accumulate an evidence base for future changes, so they need to welcome and encourage proposals for system changes to be undertaken over the long-term, alongside quick fix remedial actions.

\subsection{Integrating HFE in healthcare incident analysis}

The addition of HFE input in this study took less than a working week of the HFE researchers' time, and two to three hours for each individual healthcare stakeholder participant. The HFE expertise can be utilised throughout the whole investigation process, but can also be tapped at the last stage of analysis and recommendation development as demonstrated in this study. The major obstacle could be to get relevant healthcare stakeholders in the same location, at the same time, for the two to three hours needed for the workshops as we experienced in this study.

Systemic analysis can be effectively used to conduct analyses on batches of similar incidents. Leveson, et al (2016) used 30 adverse cardiovascular surgery events using one safety control structure with various control flaws from all incidents overlaid. This both increases the quality of the analysis through the additional data and cuts the time 
taken for each individual analysis. Although slowing the response to each individual incident these would be actioned through initial RCA analysis, with the HFE analysis providing a review process. In this way, HFE expertise can be effectively utilised in collaboration with healthcare professionals.

\section{Conclusions and future research}

The present study raises the possibility that HFE expert-facilitated systemic accident analysis with healthcare stakeholders can enable effective and efficient patient safety incident investigation identifying remedial actions on underlying system issues beyond individual issues. This study offers insights into how human factors expertise and approach can be integrated into patient safety incident investigation practice.

This study is limited in having a single case study design, multiple case studies would improve generalisability. HFE practitioners could assist at organisational and/or regional level. Currently within UK healthcare serious incident reports are reviewed/approved at regional level by patient safety managers and HFE practitioner involvement could occur at this juncture. However, it is also possible that the ability to influence safety practice could be strengthened by working closely with healthcare providers through the collaborative incident investigation at organisational level. Research would also benefit from following the case through to implementation of change, which was not possible in this study. 
Future studies would also benefit from multiple incident analysis and increased numbers of participants evaluating systemic approaches for usability and utility in different healthcare contexts and settings.

\section{Acknowledgements}

The authors would like to thank Leicestershire Improvement, Innovation and Patient Safety Unit (LIIPS) for their support in organising the workshops and the workshop participants for their inputs. We also would like to thank $\operatorname{Dr}$ Diane Ketley for her comments on the paper.

\section{References}

Salmon P, Lenné M, Stanton N, Jenkins D. Human Factors Methods and Accident Analysis. Farnham: Ashgate, 2011.

Wu AW, Lipshutz AKM, Pronovost PJ. Effectiveness and efficiency of root cause analysis in medicine. JAMA 2008;299:685-7. doi.org/10.1001/jama.299.6.685

Peerally MF, Carr S, Waring J, Dixon-Woods M. The problem with root cause analysis. BMJ Qual Saf 2016;0:1-6. doi:10.1136/bmjqs-2016-005511

Kellogg KM, Hettinger Z, Shah M et al. Our current approach to root cause analysis: is it contributing to our failure to improve patient safety? BMJ Qual Saf [Internet]. 
2016;(December):bmjqs-2016-005991.

Available

from:

http://qualitysafety.bmj.com/lookup/doi/10.1136/bmjqs-2016-005991

Leveson N. Engineering a safer world: systems thinking applied to safety. Cambridge, MA: The MIT Press, 2012.

Hollnagel E. FRAM, the functional resonance analysis method: modelling complex socio-technical systems. Farnham: Ashgate, 2012.

Rasmussen J. Risk management in a dynamic society: a modelling problem. Saf Sci 1997;27:183-213. doi:10.1016/S0925-7535(97)00052-0

Leveson N. A new accident model for engineering safer systems. Saf Sci 2004; 42: 237-70.

Hollnagel E. Barriers and accident prevention. Farnham: Ashgate, 2004.

Rasmussen J, Svedung I. Proactive Risk Management in a Dynamic Society. Karlstad: Swedish Rescue Services Agency, 2000

Leveson N, Samost A, Dekker S, Finkelstein S, Raman J. A Systems Approach to Analyzing and Preventing Hospital Adverse Events. J Patient Saf 2016. Published online first: 11 January 2016. doi:10.1097/PTS.0000000000000263

Karsh BT, Waterson, P, Holden, RJ. Crossing levels in systems ergonomics: A framework to support "mesoergonomic" inquiry. Applied Ergonomics 2014; 45:45-54. 
Alm H, Woltjer R. Patient safety investigation through the lens of FRAM. In de Waard D et al., eds. Human Factors: A system view of human, technology and organisation. Maastricht: Shaker Publishing, 2010: 153-166.

Waterson P, Catchpole K. Human factors in healthcare: welcome progress, but still scratching the surface. BMJ Qual Saf 2016;25:480-84. doi:10.1136/bmjqs-2015-005074

Leape LL, Bates DW, Cullen DJ et al. Systems analysis of adverse drug events. ADE Prevention Study Group. JAMA 1995; 274:35-43.

Bates DW, Cullen DJ, Laird N et al. Incidence of adverse drug events and potential adverse drug events. Implications for prevention. ADE Prevention Study Group. JAMA 1995;274:29-34.

Dean B, Schachter M, Vincent C, Barber N. Causes of prescribing errors in hospital inpatients: a prospective study. Lancet 2002;359:1373-8.

National Patient Safety Agency (NPSA). Root Cause Analysis Investigation Tools: Three levels of RCA investigation - guidance. 2008.

Rasmussen J, Nixon P, Warner F. Human Error and the Problem of Causality in Analysis of Accidents. Philos Trans R Soc London B Biol Sci. 1990;327:449-462.

Leveson N. A systems approach to risk management through leading safety indicators. Reliab Eng Syst Saf 2015;136:17-34.

Hettinger LJ, Kirlik A, Goh YM, Buckle P. Modelling and simulation of complex sociotechnical systems: envisioning and analysing work environments. Ergonomics 2015;58:1-15. doi: 10.1080/00140139.2015.1008586 
National Patient Safety Agency (NPSA). Root Cause Analysis Investigation tools: Contributory Factors Classification Framework. 2009.

Ishikawa K. Guide to Quality Control. Asian Productivity Organization, 1982.

National Patient Safety Agency (NPSA). Root Cause Analysis (RCA) tools: analysing to identify contributory factors and root causes. http://www.nrls.npsa.nhs.uk/resources/?entryid45=75605 (accessed 1 November 2016)

Reason J. Engineering a Safety Culture. In: Reason J, Managing the risks of organizational accidents. Farnham: Ashgate, 1997:191-222

Meadows S, Baker K, Butler J. The Incident Decision Tree: Guidelines for Action Following Patient Safety Incidents. In: Henriksen K, Battles JB, Marks ES, Lewin DI eds. Advances in Patient Safety: From Research to Implementation (Volume 4: Programs, Tools, and Products). Agency for Healthcare Research and Quality (US), 2005.

Lundberg J, Rollenhagen C, Hollnagel E. What you find is not always what you fix-How other aspects than causes of accidents decide recommendations for remedial actions. Accid Anal Prev 2010;42:2132-9.

Lundberg J, Rollenhagen C, Hollnagel E. What-You-Look-For-Is-What-You-Find - The consequences of underlying accident models in eight accident investigation manuals. Saf Sci 2009;47:1297-1311.

Underwood P, Waterson P, Braithwaite G. "Accident investigation in the wild" - A smallscale, field-based evaluation of the STAMP method for accident analysis. Saf Sci 2016;82:129-43. 
Hollnagel E. Resilience - the Challenge of the Unstable. In: Hollnagel E, Woods DD, Leveson N, eds. Resilience Engineering: Concepts and precepts. Farnham: Ashgate, 2006: 9-17.

Mills PD, Neily J, Kinney LM, Bagian J, Weeks WB. Effective interventions and implementation strategies to reduce adverse drug events in the Veterans Affairs (VA) system. Qual Saf Heal Care 2008;17:37-46. 